Case Report

\section{Intracerebral Hemorrhage of}

\section{Brainstem in triple pregnancy after in} vitro fertilization by receiving Ovum Donation: A case report and review

\author{
Andreas Suhartoyo Winarno ${ }^{1 *}$, Lukas Schloesser ${ }^{2}$, Frederic \\ Dietzel $^{3}$, Percy Balan${ }^{1}$, Thomas Hoehn ${ }^{4}$, Monika Hampl ${ }^{1}$ and \\ Tanja Natascha Fehm ${ }^{1}$
}

'Department of Obstetrics and Gynecology, University Hospital Düsseldorf, Düsseldorf, Germany 2Department of Anesthesiology, University Hospital Düsseldorf, Düsseldorf, Germany ${ }^{3}$ Department of Radiology, University Hospital Düsseldorf, Düsseldorf, Germany ${ }^{4}$ Department of General Pediatrics, Neonatology and Pediatric Cardiology, University Hospital Düsseldorf, Düsseldorf, Germany

\section{Abstract}

Deliveries prior to 28 weeks' gestation (extreme preterm birth) pose a global health concern, according to the World Health Organization (WHO). Extreme preterm birth is associated with several complications in the newborn and management in neonatal intensive care unit would incur high expenses. In parallel, advancements in in vitro fertilization will give an opportunity for women to conceive in cases of ovarian failure. At the same time, health providers also encourage patients to receive more than one embryo simultaneously during an embryo transfer. Here we report a case of a patient in coma condition of triplet pregnancy, post ovum donation with threeembryo transfer. Following stabilization, cranial computed tomography (CCT) was performed. The result showed bleeding in the brainstem and into intraventricular spaces at $25+4$ gestation weeks. Furthermore, $\mathrm{ICH}$ during pregnancy is considered as a rare case in obstetrical field, especially involving the brainstem. This could lead to life-threatening conditions and serious disability in the future. On the fifth day of hospitalization, she suffered from pneumonia and pulmonary edema. On the eight day ( $26+5$ gestations weeks), an emergency caesarean section was performed due to fully dilated of the cervix with breech presentation of all fetuses. Mother and the children survived with some non-life-threatening disabilities.

This is the very first case reported of intracerebral hemorrhage in the brainstem in triplet pregnancy after receiving ovum donation. Heterologous conception could be an iceberg phenomenon of gestational complications among the population. Reproductive tourism could still become greater in the future.

\section{More Information}

*Address for Correspondence: Andreas Suhartoyo Winarno, Department of Obstetrics and Gynecology, University Hospital of Düsseldorf Perinatal Center Level 3, In German - Perinatalzentrum Level 1, Mooren Street 5, 40225, Düsseldorf, Nordrhein-Westfalen, Germany, Tel: +49-0211-81-07587; Email: dr.andreas.winarno@gmail.com

Submitted: 04 December 2019

Approved: 14 December 2019

Published: 16 December 2019

How to cite this article: Winarno AS, Schloesser L, Dietzel F, Balan P, Hoehn T, et al. Intracerebral Hemorrhage of Brainstem in triple pregnancy after in vitro fertilization by receiving Ovum Donation: A case report and review. Clin J Obstet Gynaecol. 2019; 2: 138-144.

DOI: dx.doi.org/10.29328/journal.cjog.1001037

Copyright: @ 2019 Winarno AS, et al. This is an open access article distributed under the Creative Commons Attribution License, which permits unrestricted use, distribution, and reproduction in any medium, provided the original work is properly cited.

Keywords: ICH: Intracerebral Hemorrhage; Triplet; Pregnancy; Prematurity; Ovum donation; IVF: In Vitro Fertilization

(2) Check for updates

\section{Introduction}

The annual incidence of hemorrhagic stroke is about 1030 cases in 100,000 people in the overall population, with an estimate of about 2 out of 15 million $(10 \%-15 \%)$ strokes annually worldwide. Hydrocephalus is highly possible to develop in $40 \%$ cases of intracerebral hemorrhage (ICH). They might require external ventricular drainage (EVD) followed with fibrinolytic agents, which are also called intraventricular fibrinolysis such as Urokinase (uPA) and tissue-type plasminogen activator (tPA) such as Actilyse or Alteplase. The commonest agent nowadays used in the United States is Tpa [1]. Furthermore, ICH during pregnancy is considered as a rare case in obstetrical field, especially involving the brainstem. This could lead to life-threatening conditions and serious disability in the future [2]. Multiple pregnancies prone higher risks of delivering the fetuses preterm due to complications such as cervical insufficiency, premature uterine contraction, pathological condition of fetus blood circulation, premature rupture of the membrane in comparison to singleton pregnancy. Deliveries prior to 28 weeks of gestational age (extreme preterm birth) are global 
health concern, according to the World Health Organization (WHO) [3]. Extreme preterm birth is still often associated with respiratory distress syndrome (RDS), bronchopulmonary dysplasia (BPD), ICH, periventricular malacia (PVL), retinopathy of prematurity (ROP), necrotizing enterocolitis (NEC) and subsequent neonatal death prior to one month of age. The survival rate of newborns born prior to 28 weeks of gestation has improved significantly over the last several decades $[3,4]$.

\section{Case History}

On the day of hospitalization, a 42-year-old patient (Gravida 11, Para 0, height $164 \mathrm{~cm}$, weight $67 \mathrm{~kg}$ ) at 25+4 weeks of gestational age (WGA) became rapidly unconscious at home. The husband promptly called for an ambulance. The ambulance team stabilized her and sent the patient immediately to our hospital. This current pregnancy was the product of in vitro fertilization with ovum donation. The physician in Ukraine had performed a three embryos transfer. Prior to this pregnancy, the patient had multiple unsuccessful intrauterine insemination and in vitro fertilization. The outcome of the pregnancy was positive blood result of ß-human choriogonadotropin (B-HCG) for several days and those pregnancies did not develop further. She had only one curettage. There was no history of high blood pressure, smoking, chronic disease or past operation. Her family risk factors are diabetes mellitus type 2 and high blood pressure.

\section{Clinical examination}

She was brought in our emergency department in 2017 with ambulance in unconscious condition. A multidisciplinary team (Internal Medicine, Anesthesiologist, Obstetrics, Neurologist and Neurosurgeon) was directly involved to assess the patient's condition. The obstetricians confirmed all the babies were vital. Due to a Glasgow coma scale of 3, the patient was intubated to secure her airway. Her blood pressure was 180/110. Following stabilization, cranial computed tomography (CCT) was performed. The result showed bleeding in the brainstem and into intraventricular spaces (Figures 1,2). The neurosurgeon performed external ventricular drain (EVD) to reduce intracranial pressure. Subsequently, the patient was sent into intensive care unit (ICU) requiring catecholamine and intrathecal thrombolytic therapy with Actilyse. A single course (two bolus injection with 24 hours interval) of antenatal steroids was administered using betamethasone $12 \mathrm{mg}$, in consideration of a high-risk pregnancy with complications. EVD could be removed on the sixth day of hospitalization. Daily visitation was performed to prove the vitality of the neonates. Cervical examination was done every two to three days. Unfortunately, on the fifth day of hospitalization, the patient suffered from pneumonia, proven by clinical and laboratory findings (Figure 3). The colleague decided to commence antibiotic treatment using

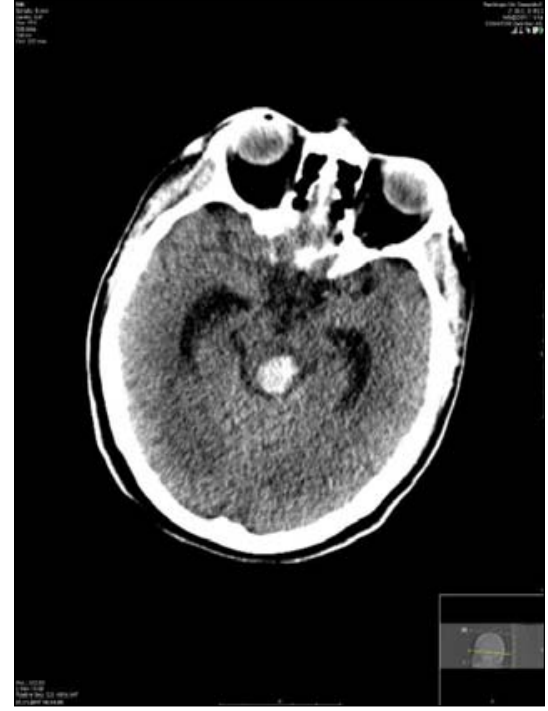

Figure 1: The computed tomography scans in axial section of the patient. It shows a bleeding area at part of the mid brain.

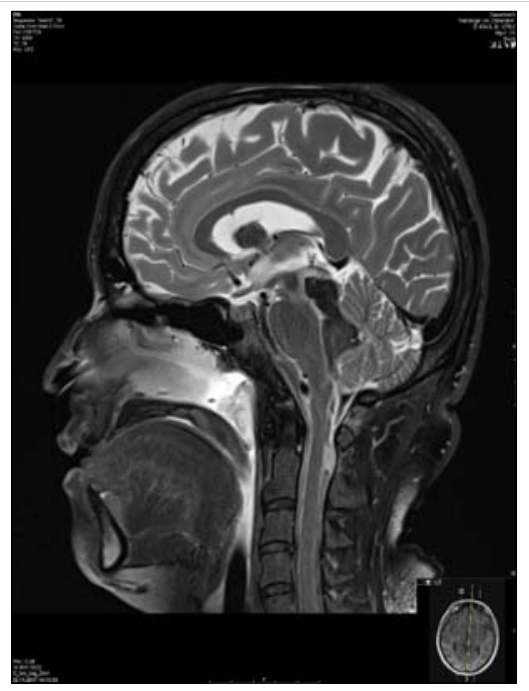

Figure 2: Shows computed tomography scan in sagittal section. It shows a bleeding area at part of the mid brain

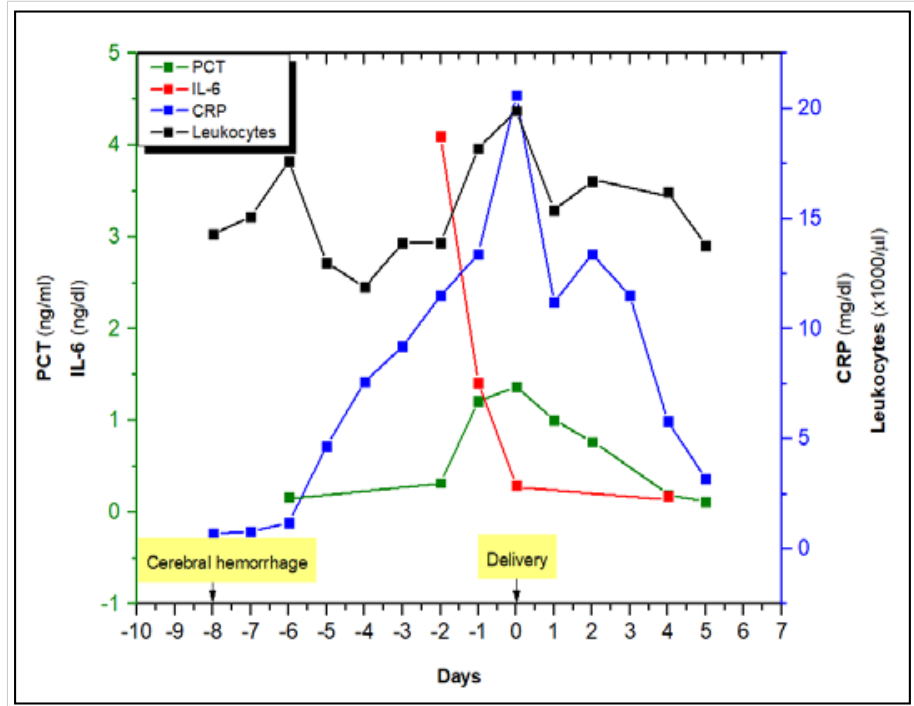

Figure 3: Shows the inflammatory findings during the treatment in ICU. Day 0 means the delivery day of this patient. 
Flucloxacillin and Ceftriaxon (Table 1). Following results of blood culture, the treatment was changed to Cefazolin. On the eighth day, fetometry was done and all of the fetuses had appropriate growth and development at 26+5 WGA, with unremarkable doppler results of the umbilical cord, medial cerebral artery, ductus venosus with positive a wave and normal level of amniotic fluid. Unexpectedly, the cervix was already completely dilated with the leading fetus with breech presentation in the vagina. An emergency caesarean section was immediately organized with the presence of three neonatologists. All of the newborns were female and delivered with breech presentations and body weights of 840 gram (g), $970 \mathrm{~g}$ and $900 \mathrm{~g}$ and the scores of appearances, pulse, grimace, activity, respiration (APGAR) on first, fifth and tenth minute were $4 / 5 / 7,2 / 4 / 7$ and 5/8/8 respectively. The arterial $\mathrm{pH}$ of the second newborn was 7.37. Examination of the other two newborns was not feasible due to lack of blood in the rest of their umbilical cords. The cause was quadruple milking of the umbilical cord during delivery to prevent the occurrence of anemia and blood transfusions in the future. Following stabilization, the neonatologists admitted all newborns into the neonatal intensive care unit (NICU) while the patient was sent back into ICU for further treatment. Weaning management was decided after careful considerations.

\section{Result}

Diagnosis of day -8: G11, P0 with ICH of brain stem et

Table 1: Shows the therapy during her treatment in ICU. Day 0 means the delivery of the babies with caesarean section.

\begin{tabular}{|l|l|l|l|l|l|l|l|l|l|} 
Medication & -8 & -7 & -6 & -5 & -4 & -3 & -2 & -1 & 0
\end{tabular} $\begin{array}{cccccccccccc}\text { Medication } & 21.11 & 22.11 & 23.11 & 24.11 & 25.11 & 26.11 & 27.11 & 28.11 & 29.11\end{array}$

\begin{tabular}{|c|c|c|c|c|c|c|c|c|c|}
\hline $\begin{array}{l}\text { Betamethasone } \\
\qquad 12 \mathrm{mg}\end{array}$ & + & + & & & & & & & \\
\hline $\begin{array}{l}\text { Actilyse } 2,5 \mathrm{mg} \\
\text { intrathecal }\end{array}$ & & + & + & + & & & & & \\
\hline $\begin{array}{l}\text { Norepinephrine } \\
\text { perfusor }\end{array}$ & + & + & + & + & + & & & & \\
\hline Urapidil perfusor & + & + & + & + & + & + & + & + & + \\
\hline Adalat $20 \mathrm{mg}$ & & & & + & + & + & & & \\
\hline $\begin{array}{l}\text { Magnesium } \\
\text { sulphate 10\% }\end{array}$ & & & & & + & + & & & \\
\hline $\begin{array}{c}\text { Clonidin } \\
\text { hydrochlorid }\end{array}$ & & & & & & & & + & + \\
\hline $\begin{array}{l}\text { Dihydralazin } \\
\text { mesilat }\end{array}$ & & & & + & + & + & + & + & + \\
\hline Propofol & + & + & & & & & & & \\
\hline Remifentanil & + & + & + & + & + & + & + & + & + \\
\hline $\begin{array}{c}\text { Isofluran } \\
\text { bronchopulmonal }\end{array}$ & & & & & & + & + & + & \\
\hline Thiopental & + & & & & & & & & \\
\hline $\begin{array}{l}\text { Midazolam } \\
50 \mathrm{mg}\end{array}$ & & & + & + & + & + & + & + & + \\
\hline Lormetazepam & & & & & & + & + & & \\
\hline Promethazine & & & & & + & + & & & \\
\hline $\begin{array}{l}\text { Heparin } 10.000 \mathrm{IU} \\
\text { perfusor }\end{array}$ & & + & + & + & + & + & + & + & + \\
\hline Flucloxacillin & & & & & & + & + & + & \\
\hline Ceftriaxone & & & & & & + & + & + & \\
\hline Cefazolin & + & & & & & & & & + \\
\hline Pantoprazol & + & + & + & + & + & + & + & + & + \\
\hline $\begin{array}{l}\text { Proteinuria mg/ } \\
\qquad \mathrm{gC}\end{array}$ & & & 304 & & & & 723 & & 1780 \\
\hline
\end{tabular}

causa preeclampsia in triple pregnancy at $25+4$ WGA after in vitro fertilization by receiving ovum donation.

Diagnosis of day-3: Hospital acquired pneumonia et causa endotracheal intubation accompanied with pulmonary edema.

Diagnosis of day 0: Complete dilatation of the cervix with breech presentation of all fetuses in an extremely preterm pregnancy at $26+5$ WGA.

\section{Outcome of mother}

After delivery, the patient was getting better from time to time and she was discharged from hospital a week after caesarean section. The patient suffered from persistent disturbance of equilibrium, double vision and vertigo at 20 months following ICH. Palsy of the trochlear nerve was diagnosed, with inferior vision worser of the left eye compared to the right eye. MRT control showed no remarkable findings. She then had a strabismus operation 19 months after the incident; however, the double vision did not improve.

\section{Outcome of newborns}

The first newborn stayed in the pediatric clinic for about six weeks. She suffered from RDS, apnea bradycardia syndrome, pulmonary hypertension and patent ductus arteriosus. At the age of three months, she suffered from coronavirus infection and moderate BPD. The control heart examination showed that at the age of one year that she had atrial septal defect secundum type 2 and persistent opening of ductus arteriosus. She suffered from pneumonia due to infection of respiratory syncytial virus (RSV) at the age of 14 months.

The second newborn stayed in the pediatric clinic for about six weeks. She suffered from RDS, apnea bradycardia syndrome, disturbance of body temperature regulation and sepsis due to abdominal infection without signs of NEC. At the age of three months, she suffered from coronavirus infection from her first sister. The control heart examination showed at the age of one year that she had persistent opening of the foramen ovale and ductus arteriosus without hemodynamic relevance. She also had delayed in increase of her body weight.

The third newborn stayed in the pediatric clinic for about five weeks. She suffered from RDS. At the age of three months, she suffered from coronavirus infection from her first sister. The control of heart examination showed at the age of one year that there was closure of ductus arteriosus without any heart abnormalities. She also suffered from bronchiolitis due to infection with respiratory syncytial virus (RSV) at the age of 14 months.

\section{Discussion}

Steptoe and Edwards were pioneers in reproductive medicine, who successfully performed the conception in 1977 and the first baby in the world was born through in vitro 
fertilization (IVF) program in the United Kingdom. Afterwards, the first oocyte donation was performed successfully in mid1980s [5]. The main reason was ovarian failure, either primary or secondary effect from old age, chemotherapy, radiotherapy, oophorectomy, Turner syndrome or other genetic disorder. The success rate was comparable to patients without ovarian failure [6].

There are three types of oocyte donation. The first type is shared oocytes meaning a woman undergoes IVF cycle for autologous purpose and at the same time donates the oocytes to other women. The second type is oocyte donation from an anonymous person with financial compensation. Nowadays, it is becoming the most popular choice because the donors are less than 35 years old with good ovarian reserves. The third type is freewill oocyte donation from family member or friend without financial compensation [7].

The practice of ovum donation in Germany is for bidden, according to the German embryo protection act (Embryonenschutzgesetz $\S 1$ Absatz 1 bis 3). It is also the same in Italy and Austria. To fulfill their wish of pregnancy when being diagnosed of ovarian failure, patients from those countries have to search for alternatives and often get treatment with oocyte donation in other countries (medical tourism for reproduction), for example in Spain, Czech Republic or Ukraine. Hence, it would be difficult to determine which type of oocyte donation was the source of perinatal complications. Furthermore, this could result in future legal conflicts due to genetic differences between mother and children. Patients usually limit such information to the physician, as safety of shared information is not warranted [8].

From the beginning of conception, physiological changes occur in maternal circulation in order to prepare good nutrition and oxygenation for the fetus. Plasma volume expands to $50 \%$ - $60 \%$ in singleton pregnancy and hemoglobin level decreases (physiological hemodilution). The decrease in platelet count is considered physiologic as long as there are more than 100.000 cells $/ \mu$ l. Cardiac output increases to about $40 \%$ more as a result of increase in stroke volume, greater muscle mass in ventricles and higher end diastolic volume in singleton pregnancy in comparison to non-pregnant condition. Physiological changes also occur in the lungs with a slight increase in pulmonary capillary wedge pressure and central venous pressure. These cause significant reduction of pulmonary vascular resistance (PVR), systemic vascular resistance (SVR), serum colloid osmotic pressure to $10 \%$ $15 \%$, osmotic pressure/pulmonary capillary wedge pressure gradient by about $30 \%$. This situation could lead to pulmonary edema. In addition, the profound pulmonary edema could be precipitated by an increase in cardiac preload (infusion of fluids or medications) or the increase of pulmonary capillary permeability (preeclampsia) [9].

Spontaneous conception in twin pregnancy varies around 8-17 per 1,000 births across the world. Assisted reproductive medicine has increased the incidence over the past two decades. Obstetric complications in twin pregnancies have been reported numerously. Preterm birth is quite common in twin gestations due to premature rupture of the fetal membranes (PPROM), cervical insufficiencies, premature contractions, iatrogenic PPROM in the case of fetal intervention, intrauterine growth retardation (IUGR) and maternal morbidity. Consequently, perinatal mortality in twin gestation is approximately six times higher than in singleton pregnancy [10]. Plasma volume in twin pregnancy could also be up to $20 \%$ more than in singleton pregnancy. The complications, which have been reported, are hypertensive disorders and preeclampsia, with relative risks of 2.04 and 2.62 respectively in comparison to singleton pregnancy. Therefore, twin pregnancies with preeclampsia prone to suffer from volume overload and pulmonary edema due to vasospasm, greater preload and afterload and increase in permeability of the capillary vessels [11].

The cause of ICH remains a big question among experts. Most of the cases reported in the literature related to intracerebral hemorrhage in pregnancy had association with arteriovenous malformation (AVM). Patients with ICH present with persistence of headache or sudden unconsciousness $[12,13]$. ICH occurring without AVM such as in this case of pregnancy has not yet been reported.

Other organs could also bleed in pregnancy such as the spleen and pancreas. Some of the cases were related to aneurysm of the artery. However, Heitkamp, et al. in the Netherlands hypothesized that estrogens and progesterones lead to degeneration of the arterial wall in spontaneous (non-traumatic) ruptured splenic artery aneurysm [14]. Furthermore, Wang, et al. [15] in China believed that minimal pressures, for example from straining during a bowel movement, coughing, vomiting, sneezing or jumping, could increase intra-abdominal pressure leading to spontaneous splenic rupture. In Australia, a case of splenic rupture after Cesarean delivery at term had been reported. According to Kenny, et al. [16], their patient complained of left upper quadrant or epigastric pain, left flank pain, chest pain, shoulder tip pain and had cardiovascular collapse. It could be difficult to differentiate the cause such as pulmonary embolism, amniotic embolism, uterine rupture, intra-abdominal bleeding of pelvic origin post-Cesarean or an injury to an abdominal viscus. They postulated hypermobility leading to repeated torsion, splenic vein spasm leading to congestion, collateral venous drainage obstruction, altered relations of abdominal organs, hypervolemia and in the case of post-Cesarean or post hysterectomy splenic rupture downward traction on omental and peritoneal attachments of the spleen or abrasion with the insertion or removal of intra-abdominal packs. There were several cases that the patients eventually died. In Italy, the autopsy showed a fibrodysplasia of the arterial wall in one case and the hilar branches in the other case [17]. In Turkey, autopsy showed retroperitoneal hematoma at the 
hilum of spleen during a religious ritual because of dissection of the vein [18]. Hamedi, et al. [19] in Iran reported a case of spontaneous splenic capsule rupture in preeclamptic cases. The team in Norway suggested that the importance of regular training in advanced traumatic life support (ATLS) principles and trauma alarm has to be done in any case of hemorrhagic shock in Obstetric emergency [20] (Table 2).

Jick, et al. [21] reported the risk of idiopathic (absence of aneurysm) ICH in non-pregnant women on oral contraceptives with differing progestagen components. This is actually a rare event and the third generation progestagen (Desogestrel, Gestodene) showed minimal increase in spontaneous ICH compared to the second generation (levonorgestrel, norgestimate). The cause of ICH remains controversial in this case as they did not explain the possible mechanism and the connection between progesterone therapy and incidence of ICH. However, an experiment using female Sprague-Dawley rats in Taiwan showed that progesterone decreased the cerebral vasospasm of traumatic cause of ICH. Moreover, progesterone could reduce apoptosis in hippocampus and cortex; the hematoma volume, cerebral edema and proinflammatory recruitment. Progesterone seems to have beneficial effects on neurobehavioral recovery and modulate neuro-inflammation [22-25].

Progesterone supplement is an important part of IVF management in terms of thickening the endometrial lining, achieving an ideal environment for embryo implantation and supporting the luteal phase $[26,27]$. The incidence of cervical painless shortening and dilatation remains unchanged in multiple pregnancy since long ago and it has been associated with preterm birth. In 2008 the ratio of infants who were born less than $1500 \mathrm{~g}$ in United States was about 1\% in singleton, $10 \%$ in twin and $36 \%$ in triplet pregnancies. The preterm birth in multiple pregnancies tend to result in infant deaths and/or suffer lifelong morbidities [28-30]. Furthermore, the progesterone supplement has become a standard procedure in the management of cervical insufficiency in the second trimester of pregnancy [31].

The increase in perinatal morbidity has been reported in cases of heterologous conceptions. Those perinatal morbidities are hypertension, intrauterine growth restriction, thrombocytopenia in the newborn and preterm birth. Pecks, et al. [8] in Germany has reported three complicated cases after receiving oocyte donation. The first patient had IUGR pregnancy as early as 16 WGA and severe preeclampsia with blood pressure reaching 220/120 at 19 WGA. Termination of pregnancy was performed at $20 \mathrm{WGA}$ due to hemodynamic insufficiency including pericardial effusion, mitral and tricuspid regurgitation and pulmonary hypertension. The patient suffered from persistent mild mitral insufficiency three months after delivery. The second and third cases were also of severe preeclampsia with HELLP syndrome with termination of pregnancy at $22 \mathrm{WGA}$, and of bilateral pleural effusion, oliguria, high transaminases level with termination of pregnancy at $26 \mathrm{WGA}$, respectively.

Another factor has to be considered is that an increased antiangiogenic profile (elevated soluble fms-like tyrosine kinase-1 (sFlt-1) and decreased placental growth factor (PIGF)), has been reported in IVF pregnancies vs spontaneous pregnancies. Higher ratio level of sFlt-1/PIGF is associated

Table 2: Showed the division of severe maternal complications. Adapted from Say L, Souza JP, Pattinson RC, WHO working group on maternal mortality and morbidity classifications. Maternal near miss-towards a standard tool for monitoring quality of maternal health care. Best Practice Resolution of Clinical Obstetrics and Gynecology 2009 ; 23: 287-296. HELLP, hemolysis, elevated liver enzymes, low platelet count; CPR, cardiopulmonary resuscitation.

\begin{tabular}{|c|c|c|c|c|c|}
\hline \multicolumn{6}{|c|}{ Potentially life-threatening conditions } \\
\hline $\begin{array}{l}\text { Hemorrhagic disorders } \\
\text { - } \quad \text { Placental abruption } \\
\text { - } \quad \text { Placenta accreta, increta or } \\
\text { - } \quad \text { Ectopic pregnancy } \\
\text { - } \quad \text { Postpartum hemorrhage } \\
\text { - } \quad \text { Ruptured uterus } \\
\text { Maternal hemorrhagic organs }\end{array}$ & \multicolumn{2}{|c|}{$\begin{array}{l}\text { Hypertensive disorders } \\
\bullet \quad \text { Severe preeclampsia } \\
\bullet \quad \text { Eclampsia } \\
\bullet \quad \text { Severe hypertension } \\
\bullet \quad \text { Hypertensive encephalopathy } \\
-\quad \text { HELLP Syndrome }\end{array}$} & \multicolumn{2}{|c|}{$\begin{array}{ll}\text { Other systemic disorders } \\
\text { - } & \text { Endometritis } \\
\text { - } & \text { Pulmonary edema } \\
\text { - } & \text { Respiratory failure } \\
\text { - } & \text { Seizure } \\
\text { - } & \text { Shock } \\
\text { - } & \text { Thrombocytopenia }<100,000 \text { platelets } \\
\text { - } & \text { Throid crisis } \\
\end{array}$} & $\begin{array}{ll}\text { Severe management indicators } \\
-\quad \text { Blood transfusion } \\
\text { - } & \text { Central venous access } \\
\text { - } & \text { Hysterectomy } \\
\text { - } & \text { ICU admission } \\
- & \text { Prolonged hospital stay (7 days) } \\
- & \text { Nonanesthetic intubation } \\
- & \text { Return to operating room } \\
\text { Surgical intervention }\end{array}$ \\
\hline \multicolumn{6}{|c|}{ Maternal near miss } \\
\hline \multicolumn{2}{|c|}{$\begin{array}{ll}\text { Clinical criteria } \\
-\quad \text { Acute cyanosis } \\
\text { - } & \text { Gasping } \\
\text { - } & \text { Respiratory rate }>40 / \text { minute or }<6 / \text { minute } \\
\text { - } & \text { Oligouria not responsive to fluids or diuretics } \\
\text { - } & \text { Clotting failure } \\
\text { - } & \text { Loss of consciousness and absence of pulse/heart } \\
\text { beat } \\
\text { Stroke } \\
\text { Uncontrollable fit/total paralysis } \\
\text { Jaundice in the presence of preeclampsia }\end{array}$} & \multicolumn{2}{|c|}{$\begin{array}{l}\text { Oxygen saturation }<90 \% \text { for } \geq 60 \text { minutes } \\
\mathrm{PaO}_{2} / \mathrm{FiO}<200 \mathrm{mmHg} \\
\text { - } \quad \text { Creatinine } \geq 300 \mu \mathrm{m} / \mathrm{L} \text { or } \geq 3.5 \mathrm{mg} / \mathrm{dL} \\
\text { Bilirubin }>100 \mu \mathrm{m} / \mathrm{L} \text { or } 6.0 \mathrm{mg} / \mathrm{dL} \\
\mathrm{pH}<7.1 \\
\text { - } \\
\text { Lactate }>5 \\
\text { Acute thrombocytopenia ( }<50,000 \text { platelets) } \\
\text { Loss of consciousness and the presence } \\
\text { of glucose and ketoacidosis in urine }\end{array}$} & \multicolumn{2}{|c|}{$\begin{array}{ll}\text { Management-based criteria } \\
-\quad \text { Use of continuous vasoactive drugs } \\
-\quad \text { Hysterectomy following infection or hemorrhage } \\
-\quad \text { Transfusion of } \geq 5 \text { units red cell } \\
-\quad \text { Intubation and ventilation } \\
-\quad \text { Dialysis for acute renal failure } \\
\text { - } \quad \text { CPR }\end{array}$} \\
\hline \multicolumn{6}{|l|}{ Maternal death } \\
\hline \multicolumn{6}{|l|}{ Severe maternal outcomes } \\
\hline
\end{tabular}


with the incidence of preeclampsia in pregnancy [32]. Unfortunately, the measurement of sFlt-1/PlGF has not been implemented yet in our clinic as a standard examination for preeclampsia patients.

According to Pecks et al., preeclampsia could be a possible explanation of sudden hypertension followed by complication with bleeding in brainstem of the patient (Figures 1,2). The magnetic resonance imaging showed no sign of arteriovenous malformation.

Computed tomography (CT) scan is the standard for evaluating ICH. In Philadelphia, America and Beijing, China, if the patients showed a clinical sign of ICH in pregnancy, the colleague would perform CT scan with lead to shield the abdomen and pelvis. However, digital subtraction angiography (DSA) is the gold standard procedure to diagnose intracranial AVM. The radiation is considered very low in both CT scan and DSA, which is equivalent to $0.17-2.8 \mathrm{mGy}$ to the fetus. The accepted limit is below 50 mGy $[33,34]$.

The opening of the cervix in this patient was a result of inflammation from pneumonia during the treatment in ICU. Any cause of inflammation will speed up the uterine contraction and cervical opening for example increase of prostaglandin secretion, tumor necrosis factor $\alpha$, Interleukin 1 and matrix metalloprotease [35] (Figure 3).

\section{Conclusion}

This is the very first case reported of intracerebral hemorrhage in the brainstem in triplet pregnancy after receiving ovum donation. Heterologous conception could be an iceberg phenomenon of gestational complications among the population. Reproductive tourism could still become greater in the future.

\section{Recommendations}

Limit in embryo transfer has to be strictly performed in consideration of possible risks and complications in multiple pregnancy. The author recommends that a maximum of two embryos can be transferred as part of in vitro fertilization. Nevertheless, this could still result in triplet or quadruplet pregnancies. Therefore, single embryo transfer is preferred to reduce perinatal and neonatal morbidity and mortality.

In the case of hemorrhages of unknown cause, a complete hormonal laboratory test would be interesting to evaluate for possible unknown hormonal associations.

Furthermore, an investigation of sFlt-1/PIGF in pregnancy with heterologous oocyte would be interesting to be evaluated.

\section{Ethical approval}

The patient has consented her approval for history, images, treatment and management related to this scientific publication of case report.

\section{Disclosure}

The patient has been consented for publication. None of the authors receives any funding. This case report is purely for scientific reasons.

\section{References}

1. Gaberel U, Montagne A, Lesept F, Gauberti M, Lemarchand E, et al Urokinase versus alteplase for intraventricular hemorrhage fibrinolysis. Neuropharmacology. 2014; 85: 158-165.

PubMed: https://www.ncbi.nlm.nih.gov/pubmed/24846802

2. Steiner $T$, Salman RAS, Beer R, Christensen $H$, Cordonnier $C$, Csiba $L$, et al. European Stroke Organisation (ESO) guidelines for the management of spontaneous intracerebral hemorrhage. Int J Stroke. 2014; 9: 840-855. PubMed: https://www.ncbi.nlm.nih.gov/pubmed/25156220

3. March of Dimes, PMNCH, Save the Children, WHO. Born Too Soon: The Global Action Report on Preterm Birth. Geneva: the World Health Organization; 2012.

4. Parry S, Strauss JF. Premature rupture of the fetal membranes. N Engl J Med. 1998; 338: 663-670.

PubMed: https://www.ncbi.nlm.nih.gov/pubmed/9486996

5. Trounson A, Mohr L. Human pregnancy following cryopreservation thawing and transfer of an eight-cell embryo. Nature. 1983; 305: 707-709. PubMed: https://www.ncbi.nlm.nih.gov/pubmed/6633637

6. Royal college of obstetricians and gynecologists. Fertility: assessment and treatment for people with fertility problems. NICE clinical guideline. 2013; 18: 394-399.

7. Shavit T, Hasson J, Ma'mari N, Son WY, Badeghiesh A, et al. Oocyte donation from donor older than 35 years. Is it worth trying? Reprod Sci. 2019; 26: 503-509.

PubMed: https://www.ncbi.nlm.nih.gov/pubmed/29806536

8. Pecks U, Maass N, Neulen J. Oocyte donation: a risk factor for pregnancy-induced hypertension. A meta-analysis and case series. Dtsch Arztebl Int. 2011; 108: 23-31.

PubMed: https://www.ncbi.nlm.nih.gov/pubmed/21285999

9. Soma-Pillay P, Nelson-Piercy C, Tolppanen H, Mebazaa A. Physiological changes in pregnancy. Cardiovasc J Afr. 2016; 27: 89-94.

PubMed: https://www.ncbi.nlm.nih.gov/pmc/articles/PMC4928162/

10. Rao A, Sairam S, Shehata. Obstetric complications of twin pregnancies. Best Pract Res Clin Obstet Gynaecol. 2004; 18: 557-576. PubMed: https://www.ncbi.nlm.nih.gov/pubmed/15279817

11. Santana DS, Cecatti JG, Surita FG, Silveira C, Costa ML, et al. Twin pregnancy and severe maternal outcomes. Obstet Gynecol. 2016; 127: 631-641.

PubMed: https://www.ncbi.nlm.nih.gov/pubmed/26959199

12. Chen J, Wang Y, Li P, Chen W, Zhou J, e al. Treatment of a giant arteriovenous malformation associated with intracranial aneurysm rtupture during pregnancy: a case report. Exp Ther Med. 2016; 12 : 1337-1340.

PubMed: https://www.ncbi.nlm.nih.gov/pmc/articles/PMC4997910/

13. Mehrotra M, Mehrotra A, Nair A, Srivastava A, Sahu RN, et al. Dissecting intracranial aneurysm in pregnancy: a rare association. Asian $\mathrm{J}$ Neurosurg. 2012; 12: 127-130.

PubMed: https://www.ncbi.nlm.nih.gov/pmc/articles/PMC5379786/

14. Heitkamp AC, Dickhoff C, Nederhoed JH, Franschman G, de Vries JI. Saved from a fatal flight: a ruptured splenic artery aneurysm in a pregnant woman. Int J Surg Case Rep. 2015; 8: 32-34. PubMed: https://www.ncbi.nlm.nih.gov/pubmed/25617728 
15. Wang C, Tu X, Li S, Luo G, Norwitz ER. Spontaneous rupture of the spleen: a rare but serious case of acute abdominal pain in pregnancy. J Emerg Med. 2011; 41: 503-506.

PubMed: https://www.ncbi.nlm.nih.gov/pubmed/20813482

16. Kenny B, Volobuev V. Splenic rupture following elective caesarean delivery at term, complicated by low-molecular-weight heparin use. Aust N Z J Obstet Gynaecol. 2007; 47: 514-516.

PubMed: https://www.ncbi.nlm.nih.gov/pubmed/17991122

17. Di Vella G, Arpaio A, Marzullo A, Colonna M. Rupture of the spleen or splenic vessels (splenic emergency syndrome) in late pregnancy: a report of two autopsy cases. Forensic Sci Int. 2008; 176: 1-5. PubMed: https://www.ncbi.nlm.nih.gov/pubmed/17728086

18. Turan N, Oghan F, Boran T. Spontaneous rupture of splenic vein in a pregnant woman during a religious ritual. J Forensic Leg Med. 2007; 14: $440-443$.

PubMed: https://www.ncbi.nlm.nih.gov/pubmed/17720597

19. Hamedi B, Shomali Z. Postpartum spontaneous rupture of spleen in a woman with severe preeclampsia: a case report and review of the literature. Bull Emerg Trauma. 2013; 1:46-48.

PubMed: https://www.ncbi.nlm.nih.gov/pubmed/27162822

20. Kazaryan AM, Wiborg J, Hauss K, Anundsen TK, Flemmen OJ, et al Spontaneous non-traumatic massive intra-abdominal spleen bleeding in young females: importance of ATLS principles and trauma alarm. Am J Case Rep. 2014; 15: 189-193.

PubMed: https://www.ncbi.nlm.nih.gov/pmc/articles/PMC4020906/

21. Jick SS, Myers MW, Jick H. Risk of idiopathic cerebral haemorrhage in women on oral contraceptives with differing progestagen components. Lancet 1999; 354: 302-303.

PubMed: https://www.ncbi.nlm.nih.gov/pubmed/10440310

22. O'Connor CA, Cernak I, Vink R. Effects of progesterone on neurologic and morphologic outcome following diffuse traumatic brain injury in rats. Experimental Neurol. 2007; 205: 145-153.

23. Chang CM, Su YF, Chang CZ, Chung CL, Tsai YJ, et al. Progesterone attenuates experimental subarachnoid hemorrhage-induced vasospasm by upregulation of endothelial nitric oxide synthase via akt signalling pathway. Biomed Res Int. 2014; 207616: 1-6.

PubMed: https://www.ncbi.nlm.nih.gov/pmc/articles/PMC4052693/

24. Lei B, Wang H, Jeong S, Hsieh JT, Majeed M, et al. Progesterone improves neurobehavioral outcome in models of intracerebral hemorrhage. Neuroendocrinology 2016; 103: 665-677.

PubMed: https://www.ncbi.nlm.nih.gov/pubmed/26562172

25. Hsieh JT, Lei B, Sheng H, Venkatraman T, Lascola CD, et al. Sex-specific effects of progesterone on early outcome of intracerebral hemorrhage. Neuroendocrinology. 2016; 103: 518-530.

PubMed: https://www.ncbi.nlm.nih.gov/pubmed/26356626
26. De Ziegler D, Pirtea P, Andersen CY, Ayoubi JM. Role of gonadotropinreleasing hormone agonists, human chorionic gonadotropin (hCG), progesterone, and estrogen in luteal phase support after hCG triggering, and when in pregnancy hormonal support can be stopped. Fertil Steril. 2018; 109: 749-755.

PubMed: https://www.ncbi.nlm.nih.gov/pubmed/29778367

27. Thomsen LH, Kesmodel US, Andersen CY, Humaidan P. Daytime Variation in Serum Progesterone during the Mid-Luteal Phase in Women Undergoing In Vitro Fertilization Treatment. Front Endocrinol (Lausanne). 2018; 9: 1-10.

PubMed: https://www.ncbi.nlm.nih.gov/pubmed/29615975

28. Aguilera M, Ramin K, Nguyen R, Giacobbe L, Swartout J. Emergency cerclage placement in multifetal pregnancies with a dilated cervix and exposed membranes: case series. AJP Rep. 2013; 3: 1-4. PubMed: https://www.ncbi.nlm.nih.gov/pubmed/23943699

29. Mathews TJ, MacDorman MF. Infant mortality statistics from the 2006 period linked birth/infant death data set. Natl Vital Stat Rep. 2010; 58: 1-31. PubMed: https://www.ncbi.nlm.nih.gov/pubmed/20815136

30. Martin JA, Hamilton BE, Sutton PD, Ventura SJ, Mathews TJ, et al. Births: Final data for 2008. Natl Vital Stat Rep. 2010; 59: 1-72. PubMed: https://www.ncbi.nlm.nih.gov/pubmed/22145497

31. American College of Obstetricians and Gynecologists. ACOG practice bulletin no. 142: Cerclage for the management of cervical insufficiency. Obstet Gynecol. 2014; 123: 372-379.

PubMed: https://www.ncbi.nlm.nih.gov/pubmed/24451674

32. Lee MS, Cantonwine D, Little SE, McElrath TF, Parry SI, et al. Angiogenic markers in pregnancies conceived through in vitro fertilization. Am J Obstet Gynecol. 2015; 212: e1-e8.

PubMed: https://www.ncbi.nlm.nih.gov/pubmed/25797229

33. Porras JL, Yang W, Philadelphia E, Law J, Garzon-Muvdi T, et al. Hemorrhage risk of brain arteriovenous malformations during pregnancy and puerperium in a north America cohort. Stroke 2017; 48: 1507-1513.

PubMed: https://www.ncbi.nlm.nih.gov/pubmed/28487334

34. Liu XJ, Wang S, Zhao YL, Teo M, Guo P, et al. Risk of cerebral arteriovenous malformation rupture during pregnancy and puerperium. Neurology. 2014; 82: 1798-1803.

PubMed: https://www.ncbi.nlm.nih.gov/pubmed/24759847

35. Deutsche- (German), Oesterreichische- (Austria), Schweizerische(Swiss) Gesellschaft fuer Gynaekologie und Geburtshilfe. Leitlinien S2k für Prävention und Therapie der Fruehgeburt (Guideline for prevention and therapy in preterm birth). Arbeitsgemeinschaft der Wissenschaftlichen Medizinischen Fachgesellschaften (AWMF) 2019; 1 (015-025): 1-227.

PubMed: https://www.ncbi.nlm.nih.gov/pmc/articles/PMC6690742/ 